\title{
Management of anticoagulant and antiplatelet therapy in patients undergoing interventional pulmonary procedures
}

\author{
Vikas Pathak ${ }^{1}$ J. Erin Allender ${ }^{2}$ and Mollie W. Grant ${ }^{2}$ \\ Affiliations: 'Dept of Pulmonary Disease and Critical Care Medicine, WakeMed Health and Hospitals, Raleigh, \\ NC, USA. ${ }^{2}$ Dept of Pharmacy, WakeMed Health and Hospitals, Raleigh, NC, USA. \\ Correspondence: Vikas Pathak, Pulmonary and Critical Care Medicine, WakeMed Health and Hospitals, \\ Raleigh, NC 27610, USA. E-mail: drvikaspathaklagmail.com
}

@ERSpublications

Available studies suggest some antithrombotic agents may be used in interventional pulmonary procedures http://ow.ly/vSF030bRqjt

Cite this article as: Pathak V, Allender JE, Grant MW. Management of anticoagulant and antiplatelet therapy in patients undergoing interventional pulmonary procedures. Eur Respir Rev 2017; 26: 170020 [https://doi.org/10.1183/16000617.0020-2017].

ABSTRACT There has been great progress in antithrombotic therapy over the past several years. Its use has increased with the advent of novel anticoagulants, as these medications do not require frequent blood tests for monitoring. Antithrombotic therapy is aimed at reducing the risk of thromboembolic events in patients with atrial fibrillation, coronary artery disease, deep vein thrombosis, valvular heart disease and pulmonary embolism. These patients are often critically ill and frequently undergo urgent interventions requiring discontinuation of anticoagulant or antiplatelet therapy which can increase the risk of thrombosis; however, continuing these agents can lead to increased risk of haemorrhage.

The purpose of this article is to summarise the literature surrounding the safety of using antiplatelet and anticoagulant therapies in patients undergoing interventional pulmonary procedures.

\section{Introduction}

Interventional pulmonology is an evolving field that encompasses the management of pulmonary diseases through a minimally invasive approach [1]. Interventional pulmonology entails endoscopic management of lung parenchymal diseases, central airway diseases and pleural diseases. More specifically, lung mass, lung nodules, mediastinal and hilar lymphadenopathy, central airway obstruction, pleural effusion and pneumothorax are diseases managed endoscopically by interventional pulmonologists.

The number of interventional pulmonary procedures has grown several fold over the past few years. Given the growth of these procedures and availability of newer cancer treatments, diagnostic and therapeutic applications have expanded. This growth means more procedures in medically complex patients, including those with cardiovascular diseases. Antiplatelet therapy is commonly administered for the primary and secondary prevention of cardiovascular diseases [2, 3]. Surprisingly, statements on interventional pulmonology from the American College of Chest Physicians [4] and the European Respiratory Society/ American Thoracic Society [5] do not discuss the management of these medications in the peri-procedural

Received: March 112017 | Accepted after revision: May 052017

Conflict of interest: None declared.

Provenance: Submitted article, peer reviewed.

Copyright OERS 2017. ERR articles are open access and distributed under the terms of the Creative Commons Attribution Non-Commercial Licence 4.0. 
setting. There are some guidelines on management of antithrombotic and antiplatelet agents in patients undergoing endoscopic procedures $[6,7]$ as well as those undergoing diagnostic flexible bronchoscopy [8], but there are no specific guidelines to date regarding the management of antithrombotic agents in patients undergoing interventional pulmonary procedures.

We discuss interventional pulmonary procedures and the supporting literature individually.

\section{Selection criteria}

We searched PubMed, MEDLINE and the Cochrane Library using combinations of words that included bronchoscopy, endobronchial ultrasound guided transbronchial needle aspiration, percutaneous dilatational tracheostomy, central airway obstruction, tracheobronchial stent, pleural effusion, pneumothorax, pleuroscopy, tube thoracostomy, antiplatelet, anticoagulation and antithrombotic therapy. Non-English literature was excluded. Articles that were pertinent to this topic were included (table 1). Half-lives and reversal methods of antithrombotic agents are listed in table 2.

\section{Percutaneous dilatational tracheostomy}

Percutaneous dilatational tracheostomy (PDT) has gained widespread acceptance compared to surgical tracheostomy because it can be performed relatively quickly at the bedside, does not carry the risks of transporting a critically ill patient to the operating room and saves costs and resources of operating room staff [9]. However, bleeding is a common complication of such procedures. Several small studies have evaluated the safety of undergoing PDT in patients on anticoagulant and antiplatelet therapy.

AвоuzGheiв et al. [10] conducted a retrospective study assessing the safety of patients undergoing percutaneous tracheostomy on antiplatelet therapy. 20 patients who underwent tracheostomy during the study period received antiplatelet therapy, while 137 patients did not and constituted a control group. Patients in the antiplatelet therapy group received either clopidogrel with or without aspirin or dipyridamole with or without aspirin. Patients who had clopidogrel discontinued within 3 days of the procedure were included in the study group and patients who had not been on clopidogrel for 4 days were eligible for inclusion in the control group. Major complications were defined as reduction in haemoglobin $>2 \mathrm{~g} \cdot \mathrm{dL}^{-1}$, any reduction in haemoglobin requiring transfusion or need for surgical procedure to control bleeding. In the antiplatelet group, mean \pm SD pre- and post-procedure haemoglobin was $8.7 \pm 1.55 \mathrm{~g} \cdot \mathrm{dL}^{-1}$ and $8.6 \pm 1.41 \mathrm{~g} \cdot \mathrm{dL}^{-1}$, respectively. One patient had oozing from the tracheostomy site that stopped after application of pressure. In the control group, mean \pm SD pre- and post-procedure haemoglobin was $9.5 \pm 1.32 \mathrm{~g} \cdot \mathrm{dL}^{-1}$ and $9.5 \pm 1.34 \mathrm{~g} \cdot \mathrm{dL}^{-1}$, respectively. Five (3.6\%) patients had minor oozing for $>10 \mathrm{~min}$ after

\begin{tabular}{|c|c|c|c|c|}
\hline \multicolumn{5}{|c|}{ Thoracentesis/tube thoracostomy } \\
\hline MAHMOOD et al. [13] & Prospective & 25 & Clopidogrel, aspirin & One patient had haemothorax \\
\hline Puchalski et al. [14] & Prospective & 73 & $\begin{array}{l}\text { Clopidogrel, LMWH, UH, } \\
\text { warfarin }\end{array}$ & No bleeding \\
\hline Aвouzgheib et al. [16] & & 18 & Clopidogrel & No bleeding \\
\hline DAMmERT et al. [17] & Retrospective & 30 & Clopidogrel & No bleeding \\
\hline \multicolumn{5}{|l|}{ EBUS-TBNA } \\
\hline StATHER et al. [23] & Retrospective & 12 & Clopidogrel & No bleeding \\
\hline \multicolumn{5}{|l|}{ Transbronchial biopsy } \\
\hline ERNST et al. [25] & Prospective & 30 & Clopidogrel & $\begin{array}{l}\text { Study stopped at } 6 \text { months due to high rate } \\
\text { of bleeding }\end{array}$ \\
\hline PASIN et al. [12] & Retrospective & 36 & Bivalirudin, UH & Three minor ${ }^{\#}$ and two major ${ }^{\pi}$ bleedings \\
\hline \multicolumn{5}{|c|}{ Percutaneous thoracic aspiration } \\
\hline PIePER et al. [26] & Retrospective & 12 & Clopidogrel & One patient with major" bleeding \\
\hline
\end{tabular}


TABLE 2 Half-life and reversal of selected antithrombotic agents

$\begin{array}{cccc}\text { Agent } & \begin{array}{c}\text { Half-life with } \\ \text { normal renal } \\ \text { function }\end{array} & \begin{array}{c}\text { Reversal prior to elective } \\ \text { procedure }\end{array} & \begin{array}{c}\text { Reversal prior to urgent } \\ \text { procedure }\end{array} \\ & & \end{array}$

\begin{tabular}{|c|c|c|c|c|}
\hline \multicolumn{5}{|l|}{ Oral antiplatelet agents } \\
\hline Cyclo-oxygenase inhibitor & Aspirin & $20 \mathrm{~min}$ & NA & Platelet transfusion \\
\hline $\begin{array}{l}\text { Irreversible } \mathrm{P} 2 \mathrm{Y} 12 \mathrm{ADP} \\
\text { receptor inhibitor }\end{array}$ & Clopidogrel & $6-8 \mathrm{~h}$ & $\begin{array}{c}\text { Withhold drug } 5-10 \text { days prior to } \\
\text { procedure }\end{array}$ & $\begin{array}{c}\text { Platelet transfusion, } \\
\text { desmopressin in severe cases }\end{array}$ \\
\hline $\begin{array}{l}\text { Irreversible P2Y12 ADP } \\
\text { receptor inhibitor }\end{array}$ & Prasugrel & $2-15 \mathrm{~h}$ & $\begin{array}{l}\text { Withhold drug } 5-10 \text { days prior to } \\
\text { procedure }\end{array}$ & $\begin{array}{c}\text { Platelet transfusion, } \\
\text { desmopressin in severe cases }\end{array}$ \\
\hline $\begin{array}{l}\text { Irreversible } \mathrm{P} 2 \mathrm{Y} 12 \mathrm{ADP} \\
\text { receptor inhibitor }\end{array}$ & Ticlopidine & $12 \mathrm{~h}$ & $\begin{array}{l}\text { Withhold drug } 10-14 \text { days prior to } \\
\text { procedure }\end{array}$ & $\begin{array}{c}\text { Platelet transfusion, } \\
\text { desmopressin in severe cases }\end{array}$ \\
\hline $\begin{array}{l}\text { Reversible P2Y12 ADP } \\
\text { receptor inhibitor }\end{array}$ & Ticagrelor & $7 \mathrm{~h}$ & $\begin{array}{l}\text { Withhold drug } 5-10 \text { days prior to } \\
\text { procedure }\end{array}$ & $\begin{array}{c}\text { Platelet transfusion, } \\
\text { desmopressin in severe cases }\end{array}$ \\
\hline \multicolumn{5}{|l|}{ Oral anticoagulant agents } \\
\hline Vitamin $\mathrm{K}$ antagonist & Warfarin & $20-60 \mathrm{~h}$ & $\begin{array}{l}\text { Withhold drug } 5 \text { days prior to } \\
\text { procedure, monitor INR }\end{array}$ & $\begin{array}{c}\text { i.v. vitamin } \mathrm{K} \text {, four-factor } \mathrm{PCC} \text {, } \\
\text { three-factor } \mathrm{PCC} \text { or activated } \\
\text { PCC }\end{array}$ \\
\hline Direct factor Xa inhibitor & Rivaroxaban & $5 \mathrm{~h}$ & $\begin{array}{c}\text { Withhold drug } \geqslant 24 \text { h prior to } \\
\text { procedure }\end{array}$ & $\begin{array}{l}\text { Consider three- or four-factor } \\
\text { PCC or activated PCC }\end{array}$ \\
\hline Direct factor Xa inhibitor & Edoxaban & $10-14 \mathrm{~h}$ & $\begin{array}{c}\text { Withhold drug } \geqslant 24 \mathrm{~h} \text { prior to } \\
\text { procedure }\end{array}$ & $\begin{array}{l}\text { Consider three- or four-factor } \\
\text { PCC or activated PCC }\end{array}$ \\
\hline Direct factor $\mathrm{Xa}$ inhibitor & Apixaban & $12 \mathrm{~h}$ & $\begin{array}{l}\text { Withhold drug } \geqslant 48 \mathrm{~h} \text { prior to } \\
\text { procedures with high bleed risk; } \\
\text { withhold drug } \geqslant 24 \mathrm{~h} \text { prior to } \\
\text { procedures with low bleed risk }\end{array}$ & $\begin{array}{l}\text { Consider three- or four-factor } \\
\text { PCC or activated PCC }\end{array}$ \\
\hline Direct thrombin inhibitor & Dabigatran & $12-17 \mathrm{~h}$ & $\begin{array}{l}\text { Withhold drug } 1-2 \text { days prior to } \\
\text { procedure }\left(\mathrm{CrCl} \geqslant 50 \mathrm{~mL} \cdot \mathrm{min}^{-1}\right) \text {; } \\
\text { withhold drug } 3-5 \text { days prior to } \\
\text { procedure }\left(\mathrm{CrCl}<50 \mathrm{~mL} \cdot \mathrm{min}^{-1}\right) \text {; } \\
\text { longer for patients undergoing } \\
\text { spinal puncture or major surgery }\end{array}$ & Idarucizumab \\
\hline \multicolumn{5}{|c|}{ Parenteral anticoagulant agents } \\
\hline $\begin{array}{l}\text { Anti-Xa, antithrombin III } \\
\text { inhibitor }\end{array}$ & UFH & $60-90 \mathrm{~min}$ & $\begin{array}{c}\text { Withhold drug } 4-6 \text { h prior to } \\
\text { procedure }\end{array}$ & Protamine sulfate \\
\hline LMWH & Enoxaparin & $4.5 \mathrm{~h}$ & $\begin{array}{c}\text { Withhold drug } 24 \mathrm{~h} \text { prior to } \\
\text { procedure }\end{array}$ & Protamine sulfate \\
\hline LMWH & Dalteparin & $2.5 \mathrm{~h}$ & $\begin{array}{c}\text { Withhold drug } 24 \mathrm{~h} \text { prior to } \\
\text { procedure }\end{array}$ & Protamine sulfate \\
\hline
\end{tabular}

the procedure, four of whom required local cauterisation to control the bleeding. There were several limitations to this study. First, this was a small, retrospective study with only 20 patients evaluated in the intervention cohort. Additionally, only aspirin with or without clopidogrel therapy was evaluated (dipyridamole therapy was included in the study protocol, but no patients undergoing tracheostomy received this agent). Finally, not all patients were at steady-state serum concentrations of clopidogrel, as patients in the study group could have been included if they had discontinued clopidogrel within the past 3 days. Despite these limitations, the authors of this study concluded that it was safe to proceed with PDT without stopping clopidogrel in patients with a strong indication for antiplatelet therapy.

Studies have evaluated use of anticoagulation in patients undergoing percutaneous tracheostomy. A retrospective, observational study [11] of 118 patients receiving systemic heparin infusions while on extracorporeal membrane oxygenation (ECMO) was conducted to assess safety of PDT. Major and minor complications were assessed. 48 (40.7\%) patients received red blood cell transfusions within $24 \mathrm{~h}$ before PDT, $17(14.4 \%)$ patients received platelet transfusions and eight $(6.8 \%)$ patients received fresh frozen plasma prior to the procedure. The heparin infusions were stopped $1 \mathrm{~h}$ prior to tracheostomy and restarted immediately after completion of the procedure at the previous rate. No procedure-related deaths occurred. Major complications occurred in five $(4.2 \%)$ patients. Two $(1.7 \%)$ patients had procedure-related bleeding, two $(1.7 \%)$ patients had peri-procedural pneumothoraces and one $(0.8 \%)$ patient had sedation-related hypotension requiring brief cardiopulmonary resuscitation without neurologic sequelae. The incidence of 
minor bleeding from the tracheostomy site was $31.4 \%$, all of which were either self-limiting $(78.4 \%)$ or responded to peri-stomal compression (10.8\%), topical vasoconstrictive agents $(8.1 \%)$ or electrocauterisation (2.7\%). Based upon the low rates of major bleeding observed in this study, the authors concluded that PDT is not a contraindication to patients receiving ECMO who require full-dose anticoagulation; however, larger studies are needed to confirm these findings. Limitations of this study include its retrospective design, which relied on information documented in the medical record for review and analysis; small sample size, which reduced the power of the study to detect rare complications; and the potential for limited applicability, since the centres included in this study were highly experienced in both ECMO and PDT [11].

PASIN et al. [12] published a single-centre, retrospective study of critically ill patients undergoing percutaneous tracheostomy in a 14-bed cardiothoracic and vascular intensive care unit (ICU). 36 patients in the ICU underwent PDT during the study period, 26 of whom were on an anticoagulant. The primary end-point was major and minor bleeding episodes. Bivalirudin was the most common anticoagulant used $(n=22)$, and four patients were on a heparin infusion. Of the patients who received bivalirudin, 15 had the drug interrupted $6 \mathrm{~h}$ prior to the procedure, two patients had the drug interrupted $3 \mathrm{~h}$ prior to the procedure and five did not have the drug interrupted. None of the patients who received heparin had the drug interrupted prior to tracheostomy. The mean \pm SD pre-procedure haemoglobin concentration was 10.1 $\pm 1.15 \mathrm{~g} \cdot \mathrm{dL}^{-1}$ and the mean \pm SD platelet count was $128000 \pm 89500$ platelets $\mu \mathrm{L}^{-1}$. No patients in the study were deemed to have had procedure-related death, however 10 intra- and post-procedural complications occurred. Three patients had minor intra-procedural bleeding, two of whom were on bivalirudin at the time of the procedure. The third, who was not on anticoagulation at the time of the procedure, had minor posterior tracheal wall injury. Six patients had post-procedural complications. Three of the six post-procedure complications were due to minor bleeding, one was due to fever and two were due to major bleeding. Of note, seven out of these 10 patients with bleeding complications had a platelet count $<100000$ platelets $\mu \mathrm{L}^{-1}$ and four had platelets $<50000$ platelets $\mu \mathrm{L}^{-1}$. Two patients required transfusion. Overall, rates of severe bleeding were low in this study despite anticoagulant therapy with bivalirudin and heparin.

Limitations of this study include its retrospective design, small sample size and lack of power to detect a difference in rates of procedure-related death. Additionally, since the half-life of bivalirudin in patients with normal renal function is only $25 \mathrm{~min}$, withholding the drug $6 \mathrm{~h}$ prior to the procedure would have allowed for the drug to be completely cleared. In addition, since several patients had thrombocytopenia at baseline, they were already at a high risk of PDT-related bleeding.

Overall, these studies demonstrated low rates of major bleeding in patients who underwent percutaneous tracheostomy while receiving antiplatelet therapy with clopidogrel with or without aspirin or anticoagulant therapy with bivalirudin or heparin. However, anticoagulation was withheld for several hours prior to the procedure for many patients, potentially allowing for partial or full elimination of the medication. Additionally, clopidogrel was stopped for as many as 3 days, which may have contributed to a low incidence of bleeding. In contrast, the risk of minor bleeding may be increased with peri-procedural use of anticoagulants and antiplatelet agents, although most bleeds could be successfully managed with electrocauterisation, compression or application of topical vasoconstrictors. Patients with pre-existing thrombocytopenia appear to be at greater risk of bleeding.

\section{Tube thoracostomy and thoracentesis}

Although small, several studies have been published evaluating chest tube placement (tube thoracostomy) and thoracentesis in patients on clopidogrel therapy. MAHMOOD et al. [13] conducted a prospective cohort study to assess the safety of therapeutic thoracentesis and small-bore chest tube placement in patients taking clopidogrel. 25 patients consented to continuation of their home clopidogrel regimens. This group was compared to a control group of 50 patients for whom clopidogrel was withheld prior to either pulmonary procedure. Patients were excluded if they had an international normalised ratio (INR) $>2$, or a platelet count $<50000$ platelets $\mu \mathrm{L}^{-1}$. Full-dose anticoagulation was withheld for all procedures. Procedural complications were defined as a decrease in haemoglobin $>2 \mathrm{~g} \cdot \mathrm{dL}^{-1}$, evidence of reaccumulation of pleural fluid on the chest radiograph within $24 \mathrm{~h}$ for the procedure, or haemothorax. Of the 25 patients taking clopidogrel, $22(88 \%)$ were on concomitant aspirin therapy. The mean \pm SD pre- and post-procedural haemoglobin in the clopidogrel group was $9.7 \pm 1.3 \mathrm{~g} \cdot \mathrm{dL}^{-1}$ and $9.6 \pm 1.5 \mathrm{~g} \cdot \mathrm{dL}^{-1}$, respectively $(\mathrm{p}=0.49)$. The mean \pm SD pre- and post-procedure haemoglobin in the control group was $10.3 \pm 1.4 \mathrm{~g} \cdot \mathrm{dL}^{-1}$ and 10.4 $\pm 1.3 \mathrm{~g} \cdot \mathrm{dL}^{-1}$, respectively $(\mathrm{p}=0.38)$. In addition, there was no significant difference in the rate of reaccumulation of pleural effusion after the procedures. One (4\%) patient on clopidogrel experienced a haemothorax after thoracentesis and required two units of packed red blood cells and small-bore chest tube placement.

Limitations of this study include the small sample size and lack of statistical power to detect a significant difference in bleeding between clopidogrel and control groups given the low reported incidence of 
haemothorax. In addition, all procedures were performed with ultrasound guidance and by interventional pulmonologists, or physicians under training (fellows) under close supervision, which may have impacted the low incidence of adverse events. Additionally, since this trial was not randomised, it is possible that only patients who consented to continue antiplatelet therapy prior to these procedures were at low bleed risk. The authors concluded that the bleeding outcomes seen in this trial were low enough to warrant a larger randomised trial to further assess the safety of clopidogrel continuation during these procedures.

PUCHALSKI et al. [14] conducted a prospective single-centre observational study of 312 patients undergoing thoracentesis, 130 (42\%) of whom had a bleeding risk. Out of these 130 patients, 15 were on clopidogrel, 14 were on either low molecular weight heparin or unfractionated heparin and 44 patients had an INR $>1.5$ due to liver disease or warfarin. The authors did not find any increased risk of bleeding in these patients and concluded that thoracentesis may be safe to perform in patients receiving anticoagulants such as warfarin, heparin and clopidogrel.

ZALT et al. [15] conducted a prospective study of 30 patients who received clopidogrel within $24 \mathrm{~h}$ of an emergent, therapeutic ultrasound-guided thoracentesis and continued therapy after the procedure. 46 procedures were completed over the course of 26 months. The primary outcome was to determine whether clopidogrel increased the risk of bleeding during and after thoracentesis. Patients were excluded if they had platelet counts $<100000$ platelets $\mu \mathrm{L}^{-1}$ or an INR $>1.5$. Only one patient developed procedure-related bleeding, defined as a small subcutaneous haematoma at the puncture site. Haemostasis was achieved with manual compression and no decline in haemoglobin was observed. As with prior studies, this study was limited by its small sample size and lack of a comparator group.

Another retrospective study [16] was conducted to assess the safety of therapeutic chest tube placement in patients on clopidogrel therapy. Major complications were defined as reduction in haemoglobin $>2 \mathrm{~g} \cdot \mathrm{dL}^{-1}$, need for transfusion, bleeding necessitating admission to the ICU or need for another procedure to stop the bleeding. Minor complications were defined as a reduction in haemoglobin $1-2 \mathrm{~g} \cdot \mathrm{dL}^{-1}$ within $24 \mathrm{~h}$ of chest tube insertion and/or local bleeding lasting $>10 \mathrm{~min} .18$ patients who underwent 24 ultrasound-guided chest tube insertions while on clopidogrel therapy were included. 13 out of the 18 patients were on concomitant aspirin. No major or minor complications were documented in any patient. As with prior studies, limitations include the small sample size and lack of comparator group.

DAMMERT et al. [17] conducted a retrospective review of 30 patients who underwent 43 small-bore $(8,14$ or $16 \mathrm{Fr}$ ) chest tube insertions (Seldinger technique) while on clopidogrel. The primary end-point was any significant bleeding complication defined as a reduction in haemoglobin $>2 \mathrm{~g} \cdot \mathrm{dL}^{-1}$ after chest tube insertion, haemothorax, development of a chest wall haematoma or any bleeding requiring blood transfusion, surgery, additional chest tube insertion or ICU admission. 91\% of patients were receiving concomitant aspirin. All patients had a platelet count $>50000$ platelets. $\mu \mathrm{L}^{-1}$ and an $\mathrm{INR}<1.5$, with the exception of one patient with an INR of 1.7. No significant bleeding complications were noted in any patient and no patient experienced a decrease in pre- or post-haemoglobin concentrations $>1.2 \mathrm{~g} \cdot \mathrm{dL}^{-1}$.

In all these studies, thoracentesis was performed using ultrasound. Either $6 \mathrm{Fr}$ or $8 \mathrm{Fr}$ catheters were inserted using a modified Seldinger technique (over the needle). Chest tube placements were also performed using ultrasound in all the above-mentioned studies; Seldinger technique (over a guidewire) was used to insert the chest tube and the size of the chest tube varied from $8 \mathrm{Fr}$ to $16 \mathrm{Fr}$ in diameter. Chest tube diameter $>20 \mathrm{Fr}$ is considered to be large bore $[18,19]$. These studies, although small, demonstrate that continuation of clopidogrel may be safe in patients undergoing ultrasound-guided thoracentesis or small-bore chest tube insertion.

\section{Medical thoracoscopy/pleuroscopy}

Despite an exhaustive search, we could not find any literature on peri-operative management of antithrombotic therapy in patients undergoing medical pleuroscopy.

\section{Video-assisted thoracic surgery}

CERFOLIO et al. [20] conducted a prospective case-control study of 33 patients undergoing general thoracic procedures who were on antiplatelet therapy at the time of the procedure. These patients were matched to 132 controls not on antiplatelet therapy. 14 patients were on clopidogrel plus aspirin and 19 patients were on clopidogrel alone. There was no increased risk of bleeding in patients who underwent primary thoracotomy; however, two patients required "redo" thoracotomies and both had clinically significant bleeding on aspirin and clopidogrel. The authors recommended discontinuing aspirin and continuing clopidogrel monotherapy based on these results. A retrospective study [21] of 164 patients undergoing thoracoscopic surgery for lung cancer compared bleeding events in 106 patients who had interruptions of their antiplatelet therapy (median time of antiplatelet interruption was 9 days) to 58 patients who had no 
interruptions in antiplatelet therapy. Patients taking both aspirin and clopidogrel $(n=11)$ compared to those on other antiplatelet regimens had more post-operative bleeding $(\mathrm{p}=0.005)$, more chest tube drainage over a 3-day period (median (range) $1140 \mathrm{~mL}(430-2280 \mathrm{~mL})$ versus $690 \mathrm{~mL}(140-2030 \mathrm{~mL})$ ), and required more red blood cell transfusions $(p=0.003)$. Changes in haemoglobin were not significantly different between groups. Based on these findings, the authors recommended discontinuing clopidogrel and continuing aspirin alone. Limitations of this study include retrospective design, small sample size and lack of assessment of long-term oncologic outcomes of peri-operative use of antiplatelet agents. Both of these studies recommended discontinuation of dual antiplatelet therapy and continuation of a single agent. Since prior studies have shown that aspirin may not increase the risk of bleeding complications to the extent that clopidogrel does, it may be safest to recommend continuation of aspirin alone in these patients [22].

\section{Endobronchial ultrasound-guided transbronchial needle aspiration}

Endobronchial ultrasound-guided transbronchial needle aspiration (EBUS-TBNA) is a minimally invasive pulmonary procedure used to diagnose pulmonary diseases by enabling highly accurate biopsies of intrathoracic structures during bronchoscopy. STATHER et al. [23] reported 12 cases of patients on clopidogrel therapy in whom the risk of stopping therapy before EBUS-TBNA was thought to outweigh the theoretical risk of bleeding. Significant bleeding was defined as blood loss $>5 \mathrm{~mL}$ and/or requiring interruption of the procedure and/or another specific intervention, such a topical iced saline/epinephrine application. 24 lymph node stations and two lung masses were aspirated. One patient required repeat bronchoscopy after discontinuation of clopidogrel so that transbronchial biopsies could be performed. No significant bleeding was noted in any of the cases at the time of biopsy or $\leqslant 4$ weeks after the procedure.

\section{Endoscopic ultrasound}

Current guidelines on the use of antiplatelet and anticoagulant agents for patients undergoing endoscopic ultrasound (EUS) [7] recommend no interruption in therapy for patients on clopidogrel, prasugrel or ticagrelor who are undergoing diagnostic EUS. For patients undergoing high-risk procedures, including EUS with fine needle aspiration (FNA) it is recommended to discontinue therapy 5 days prior to the procedure for patients without coronary stents. For high-risk patients such as those with coronary stents, it is recommended to seek cardiologist consultation prior to discontinuing P2Y12 receptor antagonist antiplatelet therapy. It is not necessary to discontinue aspirin. With regard to oral anticoagulants, patients undergoing diagnostic EUS on warfarin may continue warfarin as long as the INR is within the therapeutic range. For patients on direct anticoagulants such as dabigatran, rivaroxaban, apixaban and edoxaban, it is recommended to omit the dose the day of the procedure. For patients undergoing EUS with FNA it is recommended to stop warfarin 5 days prior to the procedure in low-risk patients and to bridge with low molecular weight heparin in high-risk patients. Direct oral anticoagulants should be held $\geqslant 48 \mathrm{~h}$ prior to EUS with FNA for patients with normal renal function.

\section{Bronchoalveolar lavage/endobronchial biopsy/bronchial brushing}

British Thoracic Society (BTS) guidelines [8] state that minor bleeding occurs in $0.19 \%$ of patients undergoing bronchoscopy and severe bleeding occurs in $0.26 \%$ of cases. A prior study showed that clinically significant bleeding occurred in $0.83 \%$ of patients, which was increased to $1.9 \%$ with biopsy [24]. The guidelines currently recommend holding clopidogrel for 7 days prior to all bronchoscopies, and holding warfarin for 5 days prior. Low-dose aspirin can be continued. Bleed risk should be balanced with the potential benefit from such procedures. Per the BTS guidelines, clopidogrel should be held for 7 days prior to endobronchial biopsy. No guidelines exist regarding antithrombotic management before bronchial brushing specifically, hence we recommend following BTS guidelines on holding the anticoagulation prior to bronchial brushing.

\section{Transbronchial biopsy}

ERNST et al. [25] conducted a prospective cohort study of 604 patients who underwent transbronchial lung biopsy over a 13-month period. The clopidogrel group consisted of 30 (5\%) patients who had used clopidogrel within $24 \mathrm{~h}$ of the bronchoscopy. The control group consisted of the remaining 574 patients who were not using clopidogrel within $24 \mathrm{~h}$ of the study. The primary end-point was to determine whether clopidogrel increased risk of bleeding after transbronchial biopsy. Patients were excluded if they had received warfarin or heparin with 2 weeks of the endoscopic procedure or had a platelet count of $<80000$ platelets $\mu \mathrm{L}^{-1}$. The study was stopped after 6 months due to excessively high rates of bleeding in the clopidogrel group. $88 \%$ of patients in the clopidogrel group experienced bleeding. Of these bleeding episodes, $27 \%$ were considered minor bleeds, $34 \%$ were considered moderate bleeds and $27 \%$ were considered major bleeds. Additionally, $100 \%$ of patients who received both clopidogrel and aspirin experienced bleeding (50\% moderate bleeding and 50\% severe bleeding), compared to only $3.4 \%$ of control 
patients who did not receive antiplatelet therapy ( $p<0.001$ for all comparisons). Based on these results, the authors concluded that clopidogrel should be stopped 5-7 days before transbronchial biopsy per the manufacturer's recommendations to decrease risk of bleeding. The recommendations from this study are supported in the current BTS guidelines, which recommend discontinuation of clopidogrel therapy 7 days prior to transbronchial biopsy and discontinuation of warfarin 5 days prior to the procedure. For patients on warfarin, INR should be checked prior to the procedure to ensure it is $<1.5$. Low-dose aspirin therapy can be continued [8].

\section{Transthoracic needle aspiration and lung biopsy}

PIEPER et al. [26] performed a retrospective review of image-guided percutaneous core needle biopsies performed in patients with clopidogrel use within 5 days. They reported total of 63 deep biopsies performed in 63 patients with recent use of clopidogrel. Mean \pm SD time of clopidogrel abstinence before biopsy was 2.9 \pm 1.9 days (median 3 days). Lung biopsy was performed in 12 (19\%) out of 63 patients. Biopsy was performed using 19-gauge introducer and a 20-gauge Bard biopsy needle (Bard Biopsy Systems, Tempe, AZ, USA). Nine patients underwent computed tomography-guided biopsy and three patients underwent ultrasound-guided biopsy. Only one patient out of 12 was reported to have clinically significant bleeding, after injury to an intercostal artery during lung biopsy (computed tomography-guided), which was successfully treated with coil embolisation.

\section{Rigid bronchoscopy/airway stents}

Despite exhaustive literature review, no studies were found addressing these procedures, probably because they, like rigid bronchoscopy and laser therapies, are used to diagnose and treat massive haemoptysis. Other indications for rigid bronchoscopy includes foreign body retrieval, dilation of airway strictures, relief of airway obstruction, insertion of stents, laser therapy or other mechanical tumour ablation. American College of Chest Physicians guidelines [4] describe coagulopathy as a contraindication to the procedure. Many of the interventional pulmonary procedures are similar in nature to advanced gastroenterology procedures. Guidelines published by the British Society of Gastroenterology [27] on management of antithrombotic therapy in patients undergoing endoscopic procedures recommend that low-risk diagnostic procedures such as oesophagogastroduodenoscopy can be undertaken on warfarin and clopidogrel, while high-risk procedures such as biopsy and dilatation of strictures should be performed after normalising coagulopathy.

\section{Endoscopic lung volume reduction}

Lung volume reduction coil treatment is a minimally invasive procedure designed to reduce hyperinflation and improve elastic recoil in patients with severe emphysema. A recent multicentre study [28] published on coil treatment for lung volume reduction found that this strategy led to improved clinical outcomes that were sustained for $\leqslant 1$ year; however, this study excluded patients who were on antiplatelet or anticoagulant therapy at the time of the procedure. Therefore, erring on the side of caution for these patients is advised.

\section{Bronchial thermoplasty}

Bronchial thermoplasty is a procedure used to reduce the mass of airway smooth muscle and reduce the incidence of bronchoconstriction. The Asthma Intervention Research (AIR) Trial Study group [29] has conducted two studies assessing bronchial thermoplasty for asthma control, which have shown improved clinical outcomes for up to 5 years post-procedure [30]. While neither of these studies specifically addressed the use of antiplatelet or anticoagulant therapy, the manufacturer currently recommends withholding antiplatelet and anticoagulant therapy prior to the procedure, as with other bronchoscopic procedures.

\section{Conclusion}

Although available studies surrounding the use of antiplatelet and anticoagulant therapy in patients undergoing pulmonary procedures are small in size, the findings suggest that use of these agents does not significantly increase the risk of major bleeding, with the exception of transbronchial biopsy and patients on dual antiplatelet therapy with aspirin and clopidogrel undergoing video-assisted thoracic surgery; however, larger studies are needed to confirm whether these practices are safe. Additionally, current studies have yet to identify whether these procedures can safely be performed in patients on other antiplatelet agents such as ticagrelor and prasugrel or direct oral anticoagulants such as dabigatran, apixaban, rivaroxaban or edoxaban. Until further studies are available, clinicians should be advised to err on the side of caution with regard to performing interventional pulmonology procedures. Continuation of aspirin alone is generally accepted for patients undergoing interventional pulmonology procedures; however, in the absence of larger studies, our recommendation would be to discontinue P2Y12 ADP 
receptor inhibitors including clopidogrel, prasugrel and ticagrelor 5-7 days prior to the procedure. In addition, we recommend discontinuing warfarin 5 days prior to the procedure and monitoring the INR to ensure that it has normalised. In the event that urgent reversal is needed, we recommend normalising the coagulopathy with use of reversal agents [31-35] if clinically possible before the procedure. However, clinical discretion, urgency of the procedure and benefit versus risk should be taken into account before the decision is made to proceed with or forgo these procedures.

\section{Acknowledgements}

Author contributions were as follows. Vikas Pathak: conception and design, data accumulation and manuscript preparation; J. Erin Allender: manuscript preparation; Mollie W. Grant: data accumulation and manuscript preparation.

\section{References}

1 Czarnecka K, Yasufuku K. Interventional pulmonology: focus on pulmonary diagnostics. Respirology 2013; 18: $47-60$.

2 Levine GN, Bates ER, Blankenship JC, et al. 2011 ACCF/AHA/SCAI guideline for percutaneous coronary intervention. A report of the American College of Cardiology Foundation/American Heart Association Task Force on Practice Guidelines and the Society for Cardiovascular Angiography and Interventions. J Am Coll Cardiol 2011; 58: e44-e122.

3 Levine GN, Bates ER, Blankenship JC, et al. 2011 ACCF/AHA/SCAI guideline for percutaneous coronary intervention: a report of the American College of Cardiology Foundation/American Heart Association Task Force on Practice Guidelines and the Society for Cardiovascular Angiography and Interventions. Catheter Cardiovasc Interv 2013; 82: E266-E355.

4 Ernst A, Silvestri GA, Johnstone D Interventional pulmonary procedures: guidelines from the American College of Chest Physicians. Chest 2003; 123: 1693-1717.

5 Bolliger CT, Mathur PN, Beamis JF, et al. ERS/ATS statement on interventional pulmonology. European Respiratory Society/American Thoracic Society. Eur Respir J 2002; 19: 356-373.

6 Anderson MA, Ben-Menachem T, Gan SI, et al. Management of antithrombotic agents for endoscopic procedures. Gastrointest Endosc 2009; 70: 1060-1070.

7 Veitch AM, Vanbiervliet G, Gershlick AH, et al. Endoscopy in patients on antiplatelet or anticoagulant therapy, including direct oral anticoagulants: British Society of Gastroenterology (BSG) and European Society of Gastrointestinal Endoscopy (ESGE) guidelines. Gut 2016; 65: 374-389.

8 Du Rand IA, Blaikley J, Booton R, et al. British Thoracic Society guideline for diagnostic flexible bronchoscopy in adults: accredited by NICE. Thorax 2013; 68: Suppl. 1, i1-i44.

9 Freeman BD, Morris PE. Tracheostomy practice in adults with acute respiratory failure. Crit Care Med 2012; 40: 2890-2896.

10 Abouzgheib W, Meena N, Jagtap P, et al. Percutaneous dilational tracheostomy in patients receiving antiplatelet therapy: is it safe? J Bronchology Interv Pulmonol 2013; 20: 322-325.

11 Braune S, Kienast S, Hadem J, et al. Safety of percutaneous dilatational tracheostomy in patients on extracorporeal lung support. Intensive Care Med 2013; 39: 1792-1799.

12 Pasin L, Frati E, Cabrini L, et al. Percutaneous tracheostomy in patients on anticoagulants. Ann Card Anaesth 2015; 18: 329-334

13 Mahmood K, Shofer SL, Moser BK, et al. Hemorrhagic complications of thoracentesis and small-bore chest tube placement in patients taking clopidogrel. Ann Am Thorac Soc 2014; 11: 73-79.

14 Puchalski JT, Argento AC, Murphy TE, et al. The safety of thoracentesis in patients with uncorrected bleeding risk. Ann Am Thorac Soc 2013; 10: 336-341.

15 Zalt MB, Bechara RI, Parks C, et al. Effect of routine clopidogrel use on bleeding complications after ultrasound-guided thoracentesis. J Bronchology Interv Pulmonol 2012; 19: 284-287.

16 Abouzgheib W, Shweihat YR, Meena N, et al. Is chest tube insertion with ultrasound guidance safe in patients using clopidogrel? Respirology 2012; 17: 1222-1224.

17 Dammert P, Pratter M, Boujaoude Z. Safety of ultrasound-guided small-bore chest tube insertion in patients on clopidogrel. J Bronchology Interv Pulmonol 2013; 20: 16-20.

18 Maskell N, British Thoracic Society Pleural Disease Guideline Group. British Thoracic Society Pleural Disease Guidelines - 2010 update. Thorax 2010; 65: 667-669.

19 Cooke DT, David EA. Large-bore and small-bore chest tubes: types, function, and placement. Thorac Surg Clin 2013; 23: 17-24.

20 Cerfolio RJ, Minnich DJ, Bryant AS. General thoracic surgery is safe in patients taking clopidogrel (Plavix). J Thorac Cardiovasc Surg 2010; 140: 970-976.

$21 \mathrm{Yu}$ WS, Jung HS, Lee JG, et al. Safety of thoracoscopic surgery for lung cancer without interruption of anti-platelet agents. J Thorac Dis 2015; 7: 2024-2032.

22 Mantz J, Samama CM, Tubach F, et al. Impact of preoperative maintenance or interruption of aspirin on thrombotic and bleeding events after elective non-cardiac surgery: the multicentre, randomized, blinded, placebo-controlled, STRATAGEM trial. Br J Anaesth 2011; 107: 899-910.

23 Stather DR, MacEachern P, Chee A, et al. Safety of endobronchial ultrasound-guided transbronchial needle aspiration for patients taking clopidogrel: a report of 12 consecutive cases. Respiration 2012; 83: 330-334

24 Cordasco EM Jr, Mehta AC, Ahmad M. Bronchoscopically induced bleeding. A summary of nine years' Cleveland clinic experience and review of the literature. Chest 1991; 100: 1141-1147.

25 Ernst A, Eberhardt R, Wahidi M, et al. Effect of routine clopidogrel use on bleeding complications after transbronchial biopsy in humans. Chest 2006; 129: 734-737.

26 Pieper M, Schmitz J, McBane R, et al. Bleeding complications following image-guided percutaneous biopsies in patients taking clopidogrel - a retrospective review. J Vasc Interv Radiol 2017; 28: 88-93.

27 Veitch AM, Baglin TP, Gershlick AH, et al. Guidelines for the management of anticoagulant and antiplatelet therapy in patients undergoing endoscopic procedures. Gut 2008; 57: 1322-1329. 
28 Deslee G, Klooster K, Hetzel M, et al. Lung volume reduction coil treatment for patients with severe emphysema: a European multicentre trial. Thorax 2014; 69: 980-986.

29 Cox G, Thomson NC, Rubin AS, et al. Asthma control during the year after bronchial thermoplasty. $N$ Engl $J$ Med 2007; 356: 1327-1337.

30 Thomson NC, Rubin AS, Niven RM, et al. Long-term (5 year) safety of bronchial thermoplasty: Asthma Intervention Research (AIR) trial. BMC Pulm Med 2011; 11: 8.

31 Douketis JD, Spyropoulos AC, Spencer FA, et al. Perioperative management of antithrombotic therapy: Antithrombotic Therapy and Prevention of Thrombosis, 9th ed: American College of Chest Physicians Evidence-Based Clinical Practice Guidelines. Chest 2012; 141: Suppl. 2, e326S-e350S.

32 Breuer G, Weiss DR, Ringwald J. 'New' direct oral anticoagulants in the perioperative setting. Curr Opin Anaesthesiol 2014; 27: 409-419.

33 Riley TR, Gauthier-Lewis ML, Sanchez CK, et al. Role of agents for reversing the effects of target-specific oral anticoagulants. Am J Health Syst Pharm 2017; 74: 54-61.

34 Nutescu EA, Dager WE, Kalus JS, et al. Management of bleeding and reversal strategies for oral anticoagulants: clinical practice considerations. Am J Health Syst Pharm 2013; 70: 1914-1929.

35 Frontera JA, Lewin JJ, Rabinstein AA, et al. Guideline for reversal of antithrombotics in intracranial hemorrhage: executive summary. A statement for healthcare professionals from the Neurocritical Care Society and the Society of Critical Care Medicine. Crit Care Med 2016; 44: 2251-2257. 